\title{
Exploring the emotional burdens and impact of medical negligence litigation on the plaintiff and medical practitioner: insights from Ireland
}

\author{
Mary-Elizabeth Tumelty ${ }^{* \dagger}$ (D) \\ School of Law, University College Cork, Ireland \\ *Author e-mail: mary.tumelty@ucc.ie
}

(Accepted 26 March 2021)

\begin{abstract}
Arguments for reform of the dynamic of medical negligence litigation in Ireland frequently centre on temporal and financial concerns. However, as the field of law and psychology has continued to grow, a body of international literature has emerged which recognises that litigation can have a destructive emotional impact on its participants, particularly in the context of medical negligence disputes.

This paper contributes to the discourse on law-caused harms through a critical exploration of the emotional burdens of medical negligence litigation from the perspective of both the plaintiff and medical practitioner, with reference to the findings of an empirical study (interviews with barristers, patient support groups, and medical professional bodies) and the literature. Whilst the temporal and financial efficiency of medical negligence litigation is important, if litigation can cause emotional harm, this should be considered a serious, undesirable effect of the traditional adversarial process, and may have broader implications for reform in this area.
\end{abstract}

Keywords: medical negligence litigation; law and emotions; Ireland

\section{Introduction}

'Don't ever think for a second, going to court is ever going to be, in any adversarial setting, easy'. (Barrister 3)

Internationally, studies on the medical negligence dynamic have centered on the temporal and financial burdens, with less emphasis on the psychological aspects of the litigation process. ${ }^{1}$ Over recent decades, however, litigation has been highlighted as being particularly unsuited to medical negligence disputes due to its aggressive and adversarial nature. ${ }^{2}$ This has led to increasing efforts to promote alternative forms of dispute resolution, such as mediation. ${ }^{3}$ Until relatively recently, the dominant policy agenda in Ireland in the context of medical negligence disputes has seemed to

\footnotetext{
${ }^{\dagger}$ My sincere thanks to the anonymous reviewers of this journal for their very helpful comments on earlier drafts.

${ }^{1}$ See for example A Samuels 'What can be done to reduce the damages, costs and fees paid out by the NHS for claims for medical negligence?' (2018) 86(3) Medico-Legal Journal 132; GH Ropescu 'Increased medical malpractice expenditures as a main detriment of growth in healthcare spending' (2015) 2(1) American Journal of Medical Research 80.

${ }^{2} \mathrm{~S}$ Forehand 'Helping the medicine go down: how a spoonful of mediation can alleviate the problems of medical malpractice litigation' (1998) 14 Ohio St Journal on Dispute Resolution 907; Lord Chancellor's Department Access to Justice (London, HMSO, 1996) p 170; A Campbell-Tiech 'Woolf, the adversarial system and the concept of blame' (2001) 113(2) British Journal of Haematology 261.

${ }^{3}$ Court and Civil Liability Act 2004, s 15; Mediation Act 2017.

(c) The Author(s), 2021. Published by Cambridge University Press on behalf of The Society of Legal Scholars. This is an Open Access article, distributed under the terms of the Creative Commons Attribution licence (http://creativecommons.org/licenses/by/4.0/), which permits unrestricted re-use, distribution, and reproduction in any medium, provided the original work is properly cited.
} 
focus on the direct financial cost of litigation. ${ }^{4}$ Despite developments internationally, and the contentious nature of the adversarial process, in Ireland, medical negligence disputes continue to be resolved by means of litigation. ${ }^{5}$

Whilst it is acknowledged that the litigation process may 'have therapeutic benefits', 6 a body of research has argued that litigation can have a destructive emotional impact on its participants. There have been a number of attempts to define and/or capture this phenomenon. For example, Gutheil et al coined the term 'critogenesis', which they explain 'relates to the intrinsic and often inescapable harms caused by the litigation process itself, even when the process is working exactly as it should'. ${ }^{8}$ Lees-Haley has referred to the 'group of stress problems caused by the process of litigation' as 'Litigation Response Syndrome' or 'LRS'. 9 Further definitions have been mooted in the specific context of the impact of medical negligence litigation on healthcare professionals, such as 'clinical judicial syndrome', ${ }^{10}$ and 'medical malpractice stress syndrome.. ${ }^{11}$ The lack of consensus notwithstanding, the literature speaks to the impact litigation can have on the psychological and emotional well-being of its participants. The way in which the emotional impact of litigation plays out in different jurisdictions depends on a wide range of factors relating to the civil law structures in each jurisdiction. Therefore, it is necessary to examine questions of this kind against the backdrop of the framework for individual jurisdictions, and this paper focuses on Ireland in this context.

Drawing on the findings of an empirical research study (interviews with barristers, patient support groups, and medical professional bodies) and the relevant literature, this paper contributes to the discourse in this area through the exploration of the emotional burdens and impact of medical negligence litigation, and the identification of aspects within the litigation process which cause and/or exacerbate harm, from the perspective of both the plaintiff and medical practitioner. The paper first provides a contextual overview of medical negligence litigation in Ireland. It then outlines the methodological approach of this study, and proceeds to explore the impact of litigation on the plaintiff and the medical practitioner. It will then identify and discuss elements of the process of litigation which cause and/or exacerbate emotional harm.

It is argued that evidencing the lived experience of medical negligence litigation in this context, and providing insights into the impact of 'law-caused' harm, ${ }^{12}$ is useful not only from the point of view of reforming the current dynamic, but also from an ethical lawyering perspective. As Keet et al observe:

awareness of the negative impacts of legal processes on the emotional and psychological functioning of clients is important. With greater awareness, lawyers can better prepare their clients for

\footnotetext{
${ }^{4}$ Litigation, for the purpose of this paper, is defined to include negotiated settlement and trial. See for example High Court Working Group on Medical Negligence and Periodic Payments Report on Periodic Payment Orders (Module 1) (2010) p 3; Department of Health 'Expert group to review the law of torts and the current systems for the management of clinical negligence claims' (2018) available at https://www.gov.ie/en/publication/e91961-expert-group-to-review-the-law-of-torts-andthe-current-systems-for-/ (last accessed 27 April 2021).

${ }^{5}$ There were 1,169 medical negligence actions commenced in 2019 in the Irish High Court. See Courts Service Annual Report (2019) p 48, available at https://www.courts.ie/annual-report (last accessed 27 April 2021).

${ }^{6} \mathrm{M}$ Keet et al 'Anticipating and managing the psychological cost of civil litigation' (2017) 34(2) Windsor Yearbook of Access to Justice 73 at 76 . See also P Case 'When the judge met P: the rules of engagement in the Court of Protection and the parallel universe of children meeting judges in the Family Court' (2019) 39(2) Legal Studies 302.

${ }^{7}$ TG Gutheil et al 'Preventing critogenic harms: minimizing emotional injury from civil litigation' (2000) 28(1) Journal of Psychiatry and Law 5 at 6; PR Lees-Haley 'Litigation response syndrome: how stress confuses the issues' (1989) 56 Defense Counsel Journal 110 .

${ }^{8}$ Gutheil et al, above n 7 , at 6 .

${ }^{9}$ Lees-Haley, above $\mathrm{n} 7$.

${ }^{10}$ I Pellino and G Pellino 'Consequences of defensive medicine, second victims, and clinical judicial syndrome on surgeons' medical practice and on health service' (2015) 67(4) Updates in Surgery 331 at 333.

${ }^{11} \mathrm{~S}$ Sanbar and M Firestone 'Medical malpractice stress syndrome' in ACLM (eds) The Medical Malpractice Survival Handbook (Elsevier, 2007) p 11.

${ }^{12}$ Gutheil et al, above $n 7$.
} 
litigation stress, and where appropriate, take preventative actions to minimize the negative aspects of the litigation experience. ${ }^{13}$

As such, the paper will argue that the need for reform of the current medical negligence dynamic in Ireland extends far beyond financial and temporal concerns, ${ }^{14}$ and will highlight the need for greater awareness of the impact of these dispute on participants.

\section{Medical negligence litigation: the Irish experience}

Medical negligence litigation is a relatively recent phenomenon in Ireland, with medical negligence claims virtually non-existent in this jurisdiction until the late $1980 \mathrm{~s} .{ }^{15}$ Although the principles underlying the tort of negligence (duty of care; breach of duty; damage; and causation) ${ }^{16}$ are applicable to claims of medical negligence, actions of the type under scrutiny have developed a jurisprudence of their own in Ireland. Thus, the principles in the context of medical negligence disputes, in particular those governing the relevant standard of care, are worthy of brief consideration. An appropriate starting point in this regard is the seminal case of Dunne $v$ National Maternity Hospital, ${ }^{17}$ a birth injury case, which established the relevant standard of care in medical negligence actions. Whilst establishing a breach of duty is a legal test, which in the course of an ordinary negligence action requires a plaintiff to establish that the standard of care provided fell below the standard required by law, in medical negligence actions the courts must defer to professional medical standards. This is because the Dunne principles provide that a plaintiff must prove that a medical practitioner acted or failed to act 'as no medical practitioner of equal specialist or general status and skill would be guilty of if acting with ordinary care' ${ }^{18}$ Whilst Dunne is the 'genesis' of the test for medical negligence in Ireland, ${ }^{19}$ and applies to cases involving diagnosis and treatment, the law in this area has evolved in relation to cases involving informed consent. In Geoghegan $v$ Harris, ${ }^{20}$ the plaintiff claimed that had he known of the risk of chronic neuropathic pain arising from bone graft surgery for the purposes of a dental implant procedure, he would not have undergone treatment. Kearns J held that the application of the reasonable patient test for the standard of disclosure was preferable to the professional standard, as outlined in Dunne. ${ }^{21}$

\footnotetext{
${ }^{13}$ Keet et al, above n 6, at 75 .

${ }^{14}$ Arguments for reform of the dynamic in Ireland thus far have largely focused on financial and temporal concerns. See for example A Sheikh 'Clinical negligence litigation: a need for change today' (2014) 20(1) Medico-Legal Journal of Ireland 2.

${ }^{15} \mathrm{~W}$ Binchy 'Tort law in Ireland: a half-century review' (2016) 56 The Irish Jurist 199 at 205; M Boylan A Practical Guide to Medical Negligence Litigation (London: Bloomsbury, 2015) p 1.

${ }^{16}$ Similar to the principles of negligence in a general context, the first element to be established is the duty of care, which is easily proven in medical negligence claims as it is long-recognised that a medical practitioner owes professional duties from the moment they assume responsibility for the care of a patient.

${ }^{17}$ Dunne v National Maternity Hospital [1989] IR 91, hereinafter Dunne.

${ }^{18}$ Dunne, ibid, at 109,110 . However an allegation based on the fact that the medical practitioner deviated from a general and approved practice will not establish negligence, unless it is also proven that the course he took was one which no medical practitioner of like specialisation and skill would have followed had he been taking the ordinary care required of a person with his qualifications; Similarly, if they pursue an alternate course of action they must show that the action is consistent with opinion within the profession, even if a minority. The principles also provide that an honest difference of opinion between two professionals will not necessarily mean one was negligent, however, if the plaintiff can establish that such practices have inherent defects which ought to have been obvious to any person giving the matter due consideration, the defendant will not escape liability. Finally, the Dunne principles provide that it is not the role of the judge to consider whether one course of action was preferable to another, but whether the conduct complained of was negligent in light of the evidence presented; see also Dunne v Eastern Regional Health Authority [2008] IEHC 315; Gottstein v Maguire [2004] IEHC 416; Griffin v Patton [2004] IESC 48.

${ }^{19}$ D O'Mahony 'Another day, another dollar - periodic payment orders for catastrophic injury claims in Ireland' (2013) 19 (2) Medico-Legal Journal of Ireland 107 at 108.

${ }^{20}$ [2000] 3 IR 536.

${ }^{21}$ The 'reasonable patient' test was endorsed by the Irish Supreme Court in Fitzpatrick $v$ White [2007] IESC 51. A similar approach has been adopted in England and Wales, see for example Montgomery v Lanarkshire Health Board [2015] UKSC 11.
} 
Following Dunne, the volume of medical negligence litigation continued to increase, with more than 1,000 medical negligence actions commenced annually in the Irish High Court. ${ }^{22}$ The increase in litigation in this area is not necessarily due to an increase in patient safety incidents ${ }^{23}$ but rather a multitude of factors, including heightened awareness of patient rights, ${ }^{24}$ the desire to prevent recurrence ${ }^{25}$ and diminishing deference towards medical practitioners. ${ }^{26}$ While the legal principles governing medical negligence disputes are of obvious importance, the focus of this paper is on the impact of litigation. As such, it is necessary to briefly consider the procedural aspects of the process. This is because, and as Montgomery observes, litigation can be seen as one of the ways in which the nature and values of the law can be established and shaped'. ${ }^{27}$

In Ireland, medical negligence claims are a category of 'personal injury' actions. ${ }^{28}$ Accordingly, medical negligence litigation is commenced by way of a personal injuries summons, issued by the legal team of the plaintiff. ${ }^{29}$ A personal injuries summons should only be issued once the medical records of the plaintiff and a supportive medico-legal expert report have been obtained. ${ }^{30}$ In accordance with the provisions of the Courts and Civil Liability Act 2004, the personal injuries summons must include the personal details of the plaintiff, specify the injuries suffered to the plaintiff as a result of the alleged negligence, detail all items of special damage which the plaintiff is claiming, contain full details in relation to the acts of the defendant(s), and outline the circumstances relating to the injury or harm alleged and all details of each instance of negligence by the defendant(s). ${ }^{31}$ On receipt of the personal injuries summons, a request for further information by the defendant(s) will frequently be the next procedural step in the litigation process, often referred to as a 'notice for particulars'. ${ }^{32}$ Following the receipt of 'particulars', a defence must be delivered which specifies the allegations of the plaintiff in the summons for which no proof is required; detail the allegations by the plaintiff in the summons of which proof is required; and outline the grounds upon which the defendant(s) claim(s) that they are not liable for the injuries

\footnotetext{
${ }^{22}$ There were 1,169 medical negligence actions commenced in the Irish High Court in 2019. See Courts Service Annual Report, above n 5 .

${ }^{23} \mathrm{AR}$ Localio et al 'Relation between malpractice claims and adverse events due to negligence: results of the Harvard Medical Practice Study III' (1991) 325(4) New England Journal of Medicine 245.

${ }^{24} \mathrm{M}$ Brazier and J Miola 'Bye-bye Bolam: a medical litigation revolution?' (2000) 8 Medical Law Review 85.

${ }^{25}$ NHS Resolution Behavioural insights into patient motivation to make a claim for clinical negligence (August 2018) https://resolution.nhs.uk/wp-content/uploads/2018/10/Behavioural-insights-into-patient-motivation-to-make-a-claim-forclinical-negligence.pdf (last accessed 19 May 2021).

${ }^{26}$ S Devaney and S Holm 'The transmutation of deference in medicine: an ethico-legal perspective' (2018) 26(2) Medical Law Review 202.

${ }^{27} \mathrm{~J}$ Montgomery 'Law and the demoralisation of medicine' (2006) 26(2) Legal Studies 185 at 189.

${ }^{28}$ Courts and Civil Liability Act 2004, s 10.

${ }^{29}$ Statute of Limitations (Amendment) Act 1991, s 3(1) as amended by the Civil Liability and Courts Act 2004, s 7 provides that an action for medical negligence must be brought within two years. In certain circumstances a plaintiff may rely on the 'date of knowledge' as per the Statute of Limitations (Amendment) Act 1991, s 2. A personal injuries summons may be issued in the District, Circuit, or High Courts depending on the value of the claim as per the Courts and Civil Law (Miscellaneous Provisions) Act 2013, Pt 3. In an effort to eliminate fraudulent claims, affidavits of verification must be sworn by the relevant party for the personal injuries summons, particulars, and defence. See also Law Society of Ireland Civil Litigation (Oxford University Press, 3rd edn, 2013) p 184.

${ }^{30}$ In order to establish the requisite elements of negligence and to obtain a medico-legal report, which is required in order to issue proceedings, the medical records of the plaintiff are of critical importance in medical negligence litigation: Reidy $v$ National Maternity Hospital [1997] IEHC 143.

${ }^{31}$ Courts and Civil Liability Act 2004, s 10(2). In many medical negligence claims there are a number of defendants. The State, via the Clinical Indemnity Scheme, which is operated by the State Claims Agency and was established in 2002, provides clinical indemnity for all healthcare providers working in public healthcare enterprises. At present, the Medical Protection Society (MPS) is the main provider of indemnity cover for physicians working in the private sector in Ireland.

${ }^{32}$ Civil Litigation, above n 29, p 203. This includes information in relation to loss of earnings and/or social welfare; additionally, details of any previous personal injury actions must be disclosed.
} 
suffered. ${ }^{33}$ Following this, both parties will then proceed to legal 'discovery', ${ }^{34}$ whereby the parties will exchange material documents pertaining to the claim. ${ }^{35}$ At this point, the litigation may proceed to settlement negotiations or trial.

The duration of medical negligence litigation in Ireland is often condemned, whether in general discursive pieces by the media, ${ }^{36}$ or by practitioners and academics. ${ }^{37}$ For example, Dowling-Hussey has asserted that 'most observers will find it uncontroversial if it is suggested that.... [plaintiffs] will face six to eight years of waiting for and taking part in court-based litigation [in Ireland]'. ${ }^{38}$ These criticisms notwithstanding, data relating to the duration of medical negligence litigation in Ireland is sparse. ${ }^{39}$

Whilst various reform measures aimed at ameliorating the perceived financial and temporal burdens of medical negligence litigation, similar to the Woolf reforms in England and Wales, such as pre-action protocols and the introduction of case management, have been considered in Ireland, ${ }^{40}$ and were recommended by the High Court Working Group on Medical Negligence in 2012, they have yet to be implemented. As such, the pace of litigation in medical negligence claims continues to be largely determined by the legal teams handling the case. Other measures, such as the promotion of mediation as an expedient, economically efficient, and non-contentious form of dispute resolution, have also been promulgated in recent years. ${ }^{41}$ However, their impact or otherwise remains to be seen. Reform measures will be further considered towards the end of this paper.

\section{Methodological approach}

Given the objective of the research, the emphasis on the nature and the impact of the phenomenon, and the level of depth required, a socio-legal methodological approach was identified as most suitable. $^{42}$

Qualitative methods were employed to explore the emotional burdens of medical negligence litigation from the perspective of the plaintiff and medical practitioner. Interviews were utilised as the instrument for data collection, ${ }^{43}$ and participants were purposively sampled based on their expertise and experience of the phenomenon under study. ${ }^{44}$ The sampling framework in this research involved

\footnotetext{
${ }^{33}$ Guidance as to the format of the defence is provided by the Courts and Civil Liability Act 2004, see Courts and Civil Liability Act 2004, s 12(1).

${ }^{34}$ RSC SI 265/1993.

${ }^{35}$ See Dunne (a minor) $v$ The National Maternity Hospital [1989] SC 350 wherein the Supreme Court held that a 'material' document is one 'relating to any matter in question in the action'.

${ }^{36}$ See for example 'Cervical cancer appeal: a rotten culture' (Irish Examiner, 18 June 2019); P Cullen 'Families and patients suffer as settlements drag on for years' (The Irish Times, 18 April 2016).

${ }^{37}$ A Dowling-Hussey 'Irish medical professional negligence claims and ADR: still under-used?' (2016) 22(2) Medico-Legal Journal of Ireland 88; Boylan, above n 15; B Glynn 'Article 6 jurisprudence on the question of delay in civil proceedings' (2019) 37(14) Irish Law Times 205.

${ }^{38}$ Dowling-Hussey, above n 37.

${ }^{39}$ One obvious source of information in relation to medical negligence claims in Ireland is the National Treasury Management Agency (NTMA), which publishes Annual Reports, including data on the Clinical Indemnity Scheme. However, an analysis of these reports found significant limitations to the data provided. A Freedom of Information (FOI) request was made by the author seeking further information, however, this request was denied.

${ }^{40}$ High Court Working Group on Medical Negligence and Periodic Payments Report on Pre-action Protocols (Module 2) (2012); High Court Working Group on Medical Negligence and Periodic Payments Report on Case Management in Clinical Proceedings (Module 3) (2013).

${ }^{41}$ Mediation Act 2017.

${ }^{42} \mathrm{R}$ Banakar and M Travers (eds) Theory and Method in Socio-Legal Research (London: Bloomsbury, 2005). Permission for this research was sought and obtained from the institutional ethics committee (The Faculty of Arts, Humanities and Social Sciences (AHSS) Research Ethics Committee in the University of Limerick) prior to engaging in any empirical research.

${ }^{43} \mathrm{R}$ Weiss Learning from Strangers: The Art and Method of Qualitative Interview Studies (Simon and Schuster, 1995).

${ }^{44} \mathrm{MD}$ Tongco 'Purposive sampling as a tool for informant selection' (2007) 5 Journal of Plants, People and Applied Research 147.
} 
12 barristers ( junior and senior counsel) who self-identified as specialists in medical negligence litigation on the Bar Council of Ireland website, ${ }^{45}$ two patient support groups (Patient Focus, and Patients for Patient Safety), ${ }^{46}$ and three Irish medical practitioner professional bodies ${ }^{47}$ (Royal College of Surgeons, Ireland; Royal College of Physicians, Ireland; and the Irish College of General Practitioners). Due to the sensitive subject matter of this research it was decided that representative groups who support plaintiffs (patients and their families) and medical practitioners through the process of litigation would be more appropriate than individual participants. Whilst this is a limitation of this research, as those who have experienced the phenomenon directly are best placed to speak to its impact, inquiring into difficult emotions had the potential to create an environment where participants would have to relive these experiences. It was recognised that representative groups have a wealth of knowledge and experience and, accordingly, their insights would be likely to answer the research question sufficiently, whilst protecting the vulnerable. ${ }^{48}$

Anonymity was guaranteed to the legal practitioners. This was achieved by assigning each participant an alpha-numeric code, eg B1 = barrister 1 , and by removing any identifying details. ${ }^{49}$ As outlined above, this research involved a number of organisations in Ireland, ie patient support groups and medical professional bodies. Given the small nature of the jurisdiction, and the fact that relatively few of these groups exist in Ireland, it was recognised that anonymity could not be guaranteed in this context. This notwithstanding, issues in relation to anonymity did not arise in the context of this research, as participants chose to be identified in this research and were happy to participate. Whilst these groups waived their rights to anonymity, every effort was made to ensure confidentiality.

Qualifying participants were sent an introductory e-mail inviting them to participate and following a response, an interview was scheduled, the location of which was mutually agreed upon. ${ }^{50}$ All interviews, except one, adopted an individual, semi-structured interview format. ${ }^{51}$ One focus group

\footnotetext{
${ }^{45}$ From this sample (34), 12 practitioners were chosen at random to be included in the study. This represented one-third of the population under study.

${ }^{46}$ Patient Focus is Ireland's leading patient advocacy group. In addition to assisting individuals who have suffered adverse healthcare events, they provide support to individuals involved in medical negligence litigation. In 2018, the patient advocacy services provided by Patient Focus moved to Sage Advocacy, https://www.sageadvocacy.ie/ (last accessed 27 April 2021). Similarly, the World Health Organisation, Patients for Patient Safety is a patient-run support group providing support to individuals who have experienced medical negligence in Ireland, https://patientsforpatientsafety.ie/ (last accessed 27 April 2021).

${ }^{47}$ An unanticipated finding of this research was that support groups for medical practitioners facing negligence actions are virtually non-existent in Ireland. However, in recognition of the need for supports for medical practitioners who are subject to medical negligence litigation, the leading medical training bodies in Ireland (the Irish College of General Practitioners (ICGP), the Royal College of Surgeons (RCSI), and the Royal College of Physicians (RCPI)) have in recent years implemented support services as part of their wider frameworks. See for example http://www.rcpi.ie/physician-wellbeing/ (last accessed 27 April 2021). Some of the professional indemnity organisations offer some limited support for their members. For example, MPS offer a 24/7 medicolegal advice phone service: see https://www.medicalprotection.org/ireland/support-advice/medicolegal-advice (last accessed 19 May 2021). The Irish Medical Organisation (IMO) is a trade union and representative body for physicians in Ireland. The IMO provides personal advice on a number of issues including medico-legal issues: see https:// www.imo.ie/join-now/benefits-of-being-a-membe/ (accessed 27 April 2021).

${ }^{48} \mathrm{~B}$ DiCicco-Bloom and B Crabtree 'The qualitative research interview' (2006) 40(4) Medical Education 314 at 319.

${ }^{49}$ Due to the small nature of the jurisdiction in which this research was carried out, the findings reported do not distinguish between 'male' and 'female' barristers, or 'junior' and 'senior' counsel. Whilst these categorisations would have been an interesting mode of analysis, these distinctions were not made when reporting the research findings in order to ensure anonymity.

${ }^{50}$ In order to ensure that volunteerism was achieved, participants were sent an information and consent letter prior to the interview. Informed consent was obtained from each participant prior to the commencement of the interview. Interviews lasted between 40 and 60 minutes: J Sieber and M Tolich Planning Ethically Responsible Research (Sage Publications, 2012).

${ }^{51} J A$ Maxwell 'Designing a qualitative study' (2008) 2 The SAGE Handbook of Applied Social Research Methods 214; HJ Rubin and IS Rubin Qualitative Interviewing: The Art of Hearing Data (Sage, 2nd edn, 2011).
} 
interview with members of the ICGP was facilitated, upon their request. ${ }^{52}$ Interviews were subsequently transcribed and coded, ${ }^{53}$ and a narrative was formed. ${ }^{54}$

\section{The plaintiff}

\section{(a) The impact of litigation}

Previous research has evidenced the profound and long-lasting impact that medical negligence litigation can have on the plaintiff. ${ }^{55}$ Cardi, for example, has compared litigation to violence, and argues that the process can cause 'serious emotional harm'. ${ }^{56}$ Winick has asserted that the stress generated from litigation 'ranks near the death of a loved one, the loss of a job, and the experience of a grave illness' and therefore frequently results in 'serious emotional costs. ${ }^{57}$ Medical negligence litigation is often inherently emotional in nature, due to the fact that such disputes frequently centre on harm and/or loss to oneself or a loved one. Additionally, and as Munford observes, 'lawsuits also cause emotional distress' ${ }^{58}$ This argument has also been recognised by Strasburger, who contends:

[T] here is an inherent irony in the judicial system in that individuals... must endure injury from the very process through which they seek redress, the legal process itself is a trauma. ${ }^{59}$

Reflecting the international literature on this subject, the findings of this research indicate that litigation often has profound and long-lasting emotional consequences for plaintiffs. ${ }^{60}$ Through the exploration of the emotional burdens of medical negligence litigation from the perspective of the plaintiff, three key impacts were identified: (i) psychological and emotional harm; (ii) arrested healing; and (iii) the impact on family.

\section{(i) Psychological and emotional harm}

Halleck has argued that 'litigation is an emotionally charged process that can have painful psychological consequences'. ${ }^{61}$ In recognition of the impact that litigation-induced harm can have on plaintiffs, a body of international literature has developed on this topic. ${ }^{62}$ For example, Lees-Haley has argued that where a plaintiff experiences a group of symptoms such as anxiety, anger, depression, which are a result of litigation-induced harm, these symptoms may be collectively recognised as 'litigation-response syndrome' (LRS), which he compares to post-traumatic stress disorder

\footnotetext{
${ }^{52}$ The group comprised of four members, all of whom had professional experience in relation to the impact of medical negligence litigation, and two of whom also had personal experience of the phenomenon. Confidentiality issues in relation to focus groups did not arise in the context of this research, as participants waived their right to anonymity. Whilst members of the focus group waived their right to anonymity, the researcher chose to only identify the professional body (ICGP), as naming individual participants in this context did not add to the explanatory power of the research findings. See I McLafferty 'Focus group interviews as a data collecting strategy' (2004) 48(2) Journal of Advanced Nursing 187.

${ }^{53} \mathrm{~J}$ Creswell Qualitative Inquiry and Research Design: Choosing Among Five Traditions (Sage, 3rd edn, 2013).

${ }^{54}$ This involved the integration of key concepts from the literature and the research findings.

${ }^{55}$ SL Halleck 'Perils of being a plaintiff: impressions of a forensic psychiatrist' (1997) 336 Clinical Orthopaedics and Related Research 72.

${ }^{56} \mathrm{~V}$ Cardi 'Litigation as violence' (2014) 49 Wake Forest Law Review 677 at 681.

${ }^{57} \mathrm{~B}$ Winick 'Therapeutic jurisprudence and the role of counsel in litigation' (2000) 37 California Western Law Review 105 at $108-109$.

${ }^{58}$ LT Munford 'The peacemaker test: designing legal rights to reduce legal warfare' (2007) 12 Harvard Negotiation Law Review 377 at 387.

${ }^{59} \mathrm{~L}$ Strasburger 'The litigant-patient: mental health consequences of civil litigation' (1999) 27(2) Journal of the American Academy of Psychiatry and the Law Online 204.

${ }^{60}$ In considering international studies it is important to recognise jurisdictional differences but nonetheless the findings are similar to those in the present study.

${ }^{61}$ Halleck, above n 55.

${ }^{62}$ Ibid; Lees-Haley, above n 7; Strasburger, above n 59.
} 
(PTSD). ${ }^{63}$ White-Stewart and Wood note that the primary difference between LRS and PTSD is that the litigation process itself triggers emotional distress, whereas PTSD generally results following exposure to a traumatic event. ${ }^{64}$ Arguably, the differences between LRS and PTSD need further investigation and clarification. As Keet et al note, one of the difficulties in this context is the challenge of 'distinguishing between the strain caused by the original loss and that caused by the process' ${ }^{65}$ This notwithstanding, these arguments highlight the destructive emotional impact litigation may have on those involved. ${ }^{66}$

The findings of this study suggest that plaintiffs find the process of medical negligence litigation to be upsetting and distressing, and the research uncovered that the impact of litigation can manifest itself in a variety of ways, including the experience of pain, anger, disappointment, and anxiety. ${ }^{67}$ Both patient support groups and a large majority of barristers spoke of these issues:

[People find the process] excruciating... painful, adds insult to injury frequently... (Patient Focus)

[People experience] the full gamut really, from basic sadness to absolute disappointment... (Patients for Patient Safety)

I think people are often worn down, particularly in the bigger cases and you see that, and they feel that they're fighting the system the whole way and they feel they're fighting for everything. (Barrister 9)

While it may be argued that experiencing emotions of this nature is a normal reaction to an emotionally charged dispute, 'intense and frequent anger can... become a destructive reaction', ${ }^{68}$ and such a combination of symptoms may lead to LRS. Lees-Haley has noted that LRS can also include symptoms such as insomnia, distressing dreams, and difficulties concentrating. ${ }^{69}$ Both patient support groups spoke to these issues, with one support group noting:

People have sleepless nights... there is a whole lot of stuff going on... emotionally, physically, intellectually, you are in a mess. (Patients for Patient Safety)

In recognition of the trauma inflicted by the litigation process, one practitioner commented:

I've never seen a plaintiff [celebrate] when they win. Actually, they usually start crying when they win the case... I don't think I've ever seen a plaintiff come out and say 'God, that was really worth it'. (Barrister 1)

Thus, whilst a plaintiff may be successful in their claim, they may not be satisfied with the outcome due to the impact of litigation on their psychological well-being, coupled with the inability of the system to address 'extra-legal' aims, for example, the desire for an apology. ${ }^{70}$

\footnotetext{
${ }^{63}$ Lees-Haley, above n 7.

${ }^{64} \mathrm{M}$ White Stewart and SM Wood 'Civil plaintiffs, trauma, and stress in the legal system' in MK Miller and BH Bornstein (eds) Stress, Trauma, and Wellbeing in the Legal System (Oxford: Oxford University Press, 2013) p 135.

${ }^{65}$ Keet et al, above n 6, at 77 .

${ }^{66}$ White Stewart and Wood, above n 64, p 135.

${ }^{67}$ Strasburger, above n 59; W Linden et al "There is more to anger coping that "in" or "out"' (2003) 3(1) Emotion 12, wherein anger is defined as 'an acute emotional response that depends on the appraisal of events and the assignment of meaning to them'; J Butcher et al Abnormal Psychology (Pearson, 17th edn, 2016) wherein anxiety is defined as a 'complex blend of unpleasant emotions and cognitions', which may be intermittent or constant.

${ }^{68}$ Linden et al, above n 67.

${ }^{69} \mathrm{E}$ Deykin et al 'Posttraumatic stress disorder and the use of health services' (2001) 63(5) Psychosomatic Medicine 835; Lees-Haley, above n 7, at 112 .

${ }^{70}$ For a full discussion see T Relis 'It's not about the money!: a theory on misconceptions of plaintiffs' litigation aims' (2007) 68(701) University of Pittsburgh Law Review 701.
} 


\section{(ii) Arrested healing}

The findings of this research indicate that litigation can also result in 'arrested healing', which occurs when 'fixations created by the legal process ... interfere with personal and internal growth..."71 Strasburger has asserted that generally involvement in litigation prevents individuals from 'moving on'. ${ }^{72}$ Several participants in the present research spoke of this issue, which was identified as having a destructive emotional impact on the plaintiff, with one barrister commenting:

Some people... become very obsessed by their cases. (Barrister 9)

Although arrested healing generally is an undesirable impact of litigation, in the context of medical negligence litigation, arrested healing is particularly salient in wrongful death claims. Grief theorists assert that in order to make progression, one must face the loss by reflecting on the events surrounding the death and memories of the deceased, and subsequently work towards mourning and parting from the deceased. ${ }^{73}$ However, those engaged in litigation must 'relive the event, re-experience the pain, and in general remain almost frozen in time until the claim is resolved'. ${ }^{74}$ Thus, litigation can postpone and prolong the grieving process. As Winick observes:

$[\mathrm{R}]$ ather than putting the pain and loss behind them and beginning the healing process, a lawsuit makes them relive the painful episode in ways that may prevent healing. ${ }^{75}$

Similarly, Rosenblatt has asserted that involvement in litigation 'may have profound effects on the grief process' ${ }^{76}$ Speaking on the issue of arrested healing in the context of wrongful death claims, patient support groups in the present research commented:

If it's a child that's died anger can be long lasting and it's almost a replacement for going through the bereavement process itself and people can't just move on and they hold onto the anger, because if they're holding onto the anger they're holding onto the child or the baby or the family member or the parent. (Patient Focus)

What they probably don't realise is the letting go bit, around bereavement anyway, [litigation] delays all that and you are not really able to go through the grieving process as it would naturally happen... Depending on what is happening with the litigation process, you get stuck in different points and so that's more of the abuse. I would actually call it abuse, I think it's an abusive system to do that to people who went into hospital, submitted themselves to healthcare in good faith, and something unexpected has happened and then it's almost like they are left to pick up the pieces alone. (Patients for Patient Safety)

Arrested healing in the context of medical negligence litigation is, therefore, particularly problematic. As Rosenblatt observes, ongoing litigation can leave one distressed, agitated, and unable to live with a more or less full acceptance of the death for a relatively long period of time'. ${ }^{77}$ This prevents litigants from moving on, and inevitably, delays the healing process.

\footnotetext{
${ }^{71}$ Gutheil et al, above $\mathrm{n} 7$, at 15 .

${ }^{72}$ Strasburger, above n 59, at 206.

${ }^{73} \mathrm{M}$ Stroebe and W Stroebe 'Does “grief work” work?' (1991) 59 Journal of Consulting \& Clinical Psychology 479.

${ }^{74} \mathrm{D}$ Hepler 'Providing creative remedies to bystander emotional distress victims: a feminist perspective' (1993) 14 Northern Illinois University Law Review 71 at 101.

${ }^{75}$ Winick, above n 57, at 109.

${ }^{76}$ PC Rosenblatt 'Grief and involvement in wrongful death litigation' (1983) 7(4) Law and Human Behavior 351 at 352 , 353.

${ }^{77}$ Ibid.
} 
(iii) Impact on family

Another finding of this research is the impact medical negligence litigation can have on family members of the plaintiff. Cardi has noted that the impact of the adversarial process can extend to spouses and close relatives 'who are drawn into the cycle' of litigation. ${ }^{78}$ Similarly, Lees-Haley has asserted:

[C]lose relatives, especially spouses, also can be affected by [litigation response syndrome]. Sometimes their complaints are more severe than those of the primary litigant, even when they are not themselves parties to the suit. ${ }^{79}$

In the present study, both patient support groups and a number of barristers highlighted the fact that litigation can also have a significant psychological and emotional impact on family members of the plaintiff:

The other thing that we find is that it can cause considerable grief in families. (Patient Focus)

Strasburger has commented on the impact litigation may have on family members generally, noting that the preoccupation of the plaintiff with the litigation 'often exceeds the tolerance of family members' ${ }^{80}$ Similarly, Keet et al noted that many litigants 'have a compulsive need to talk about the experience which exceeds the patient of their friends and family members'. ${ }^{81}$ As one patient group explained:

That's another thing, the impact that [litigation] has on the other members of the family. Like, if you are so immersed and embroiled in this litigation... of course, the others are going to feel neglected... and they will wonder where do they fit into the scheme of things and is the one who is either injured or gone the important one. It's hugely complex. (Patients for Patient Safety)

As previously noted, the patient-plaintiff may experience anger, but it was also recognised that litigation can have a significant impact and invoke anger in family members. Noting this, one of the patient groups commented:

Sometimes, if it's a woman that's been injured, the husband is angry on their behalf, which is difficult. (Patient Focus)

These findings suggest that litigation impacts not only its direct participants, but also their family members.

Whilst the plaintiff is the first and most obvious victim of medical negligence, it has also been recognised that litigation can have significant emotional consequences for the medical practitioner involved in the dispute. ${ }^{82}$ Therefore, it is prudent to also explore the phenomenon from the perspective of the medical practitioner.

\footnotetext{
${ }^{78}$ Cardi, above n 56.

${ }^{79}$ Lees-Haley, above n 7 , at 111.

${ }^{80}$ Strasburger, above n 59, at 205.

${ }^{81}$ Keet et al, above n 6, at 85 .

${ }^{82} \mathrm{~N}$ Ryll 'Living through litigation: malpractice stress syndrome' (2015) 34(1) Journal of Radiology Nursing 35; S Charles et al 'Physicians on trial - self-reported reactions to malpractice trials' (1988) 148(3) Western Journal of Medicine 358.
} 


\section{The medical practitioner}

\section{(a) The impact of litigation ${ }^{83}$}

A growing body of international research has illuminated the impact of litigation on medical practitioners. ${ }^{84}$ For example, Ryll has argued the 'adversarial litigation process can be traumatic to all participants ${ }^{85}$ and '... stress [as a result of litigation] evokes strong, sometimes painful, emotional and physical responses' ${ }^{86}$ However, absent from this body of research is data from Ireland. Whilst litigation may be a 'predictable hazard' of practising medicine, ${ }^{87}$ or as one barrister asserted: 'part of the cost of doing business', ${ }^{88}$ the absence of empirical insight into the impact of litigation on medical practitioners in Ireland is problematic, as an understanding of the phenomenon has important implications, for both healthcare providers and law reform.

Consistent with the international literature, the findings of this research indicate that medical negligence litigation can have a profound and long-lasting impact on medical practitioners. Four themes emerged during the data analysis: (i) emotional and psychological harm; (ii) impact on professional identity; (iii) impact on professional role; and (iv) impact on professional practice. These will now be discussed through the lens of the literature and the empirical research findings.

\section{(i) Emotional and psychological harm}

Brenner asserts than when a medical practitioner first realises that they are being sued they will feel 'numb. ${ }^{99}$ Similarly, all medical professional bodies noted that the initial notification of a claim can be quite stressful. One focus group member reflected on their personal experience with litigation and recalled:

I remember being quite sick over it. I mean not sick but just feeling 'oh God' when it first occurred - when I got the solicitor's letter from the plaintiff. (Group Member 3, ICGP)

In addition to the initial shock and worry experience by physicians, research has evidenced that litigation can have a profound emotional and psychological impact on medical practitioners. For example, Charles et al, in the context of their research with physicians in the United States, uncovered that $97 \%$ of the 64 participants surveyed acknowledged 'some physical or emotional reaction' as a response to the litigation, ${ }^{90}$ with the most frequently reported feelings amongst physicians being fear, guilt, self-doubt and shame. ${ }^{91}$ Other authors have drawn similarities between post-traumatic stress disorder (PTSD) and physicians' reactions to litigation. ${ }^{92}$ For example, Ryll has argued that a healthcare practitioner involved in litigation may experience 'medical malpractice stress syndrome' (MMSS). ${ }^{93}$ Ryll explains that MMSS is 'remarkably similar to post-traumatic stress disorder

\footnotetext{
${ }^{83} \mathrm{An}$ inherent difficulty in the context of ascertaining the impact of litigation on medical practitioners is separating the impact of an adverse event from the impact of the litigation process itself, as the two are often inextricably interwoven. See for example SC Charles 'Coping with a medical malpractice suit' (2001) 174 Western Journal of Medicine 55 who notes: 'the reaction to being sued often is prefaced by a period of emotional turmoil following the catastrophic event or negative outcome'. Despite this, in this research every effort was made to focus on the impact of litigation.

${ }^{84}$ See for example, Ryll, above n 82; Charles et al, above n 82 ; Charles, above n 83.

${ }^{85}$ Ryll, above n 82 .

${ }^{86}$ Ibid.

${ }^{87}$ Sanbar and Firestone, above n 11.

${ }^{88}$ Interview with Barrister 6.

${ }^{89}$ IR Brenner How to Survive a Medical Malpractice Lawsuit: The Physician's Roadmap for Success (John Wiley \& Sons, 2010) p 32.

${ }^{90}$ Charles et al, above $n 82$.

${ }^{91} \mathrm{~A}$ Waterman et al 'The emotional impact of medical errors on practicing physicians in the United States and Canada' (2007) 33(8) The Joint Commission Journal on Quality and Patient Safety 467; A Stangierski et al 'Medical errors - not only the patients' problem' (2012) 8 Archives of Medical Science 569; JF Christensen and PM Dunn 'The heart of darkness: the impact of perceived mistakes on physicians' (2006) 19(7) Neonatal Intensive Care 48.

${ }^{92}$ Pellino and Pellino, above n 10, at 333; Sanbar and Firestone, above n 11.

${ }^{93}$ Ryll, above n 82 .
} 
(PTSD), ${ }^{94}$ in that the healthcare practitioner may experience flashbacks, emotional numbness, guilt, and loss of interest in professional activities. ${ }^{95}$ Additionally, Pellino et al have argued that litigation-induced harm can result in 'clinical judicial syndrome', which they define as a:

series of symptoms that affect the health of [a medical practitioner]... subjected to legal proceedings... it includes all the physical, psychological and behavioral alterations that can be caused in the doctor as a result of the legal events in which he or she is involved. ${ }^{96}$

Similarly, in the context of this research, participants reported that symptoms ranged from feelings of guilt, anxiety or depression, and insomnia, to more extreme reactions such as PTSD. All professional medical bodies spoke of these issues:

Lack of sleep, recurring thoughts, a 'what if loop... Closing in, isolation, things like that. (RCPI)

Noting that in extreme instances medical practitioners may experience PTSD and will require time off work to recover, one member of the focus group, representing the views of the other members, stated:

[PTSD] happens, and in that situation where there have been flashbacks and it interferes with their practice of medicine, they actually need time off work... they're acutely distressed. (Group Member 1, ICGP)

Whilst physicians have a professional duty to look after their own health and well-being, ${ }^{97}$ the majority of medical professional bodies noted problems with medical culture and its impact on medical practitioners taking time off work:

It wouldn't be seen as a good thing if you call in sick... people turn up when they're sick, and they work when they're sick. Taking time off because you're ill would be seen (by some people) as being weak, taking time off for psychiatric illness would be seen as major weakness... (RCSI)

Trying to encourage a doctor to take time off work is very difficult and it often involves lots of people and input to enable them to take time off work... (Group Member 1, ICGP)

These findings support Ennis and Vincent's research, who have argued that failure to acknowledge the need for help is part of the problem. ${ }^{98}$ The reluctance of medical practitioners to seek help and/or take time off work is also of concern: as Bark et al observe, if a medical practitioner is under severe stress and does not take time off work to deal with MMSS or other mental health issues, their concentration may lapse, which puts them at risk of being involved in adverse events. ${ }^{99}$ The findings also speak to the need for appropriate supports for those involved in litigation. As previously noted, at present in Ireland, supports for medical practitioners in this context are limited.

(ii) Impact on professional identity

In addition to the emotional and psychological impact outlined above, the findings of this research indicate that medical negligence litigation can have a significant impact on the professional identity of the medical

\footnotetext{
${ }^{94}$ Ibid.

${ }^{95}$ Ibid.

${ }^{96}$ Pellino and Pellino, above n 10, at 333.

${ }^{97}$ Irish Medical Council Guide to Professional Conduct and Ethics for Registered Medical Practitioners (Amended) $\left(8^{\text {th }}\right.$ edn, 2019) p 38.

${ }^{98} \mathrm{M}$ Ennis and C Vincent 'The effects of medical accidents and litigation on doctors and patients' (1994) 16(2) Law and Policy 97 at 116.

${ }^{99} \mathrm{P}$ Bark et al 'Impact of litigation on senior clinicians: implications for risk management' (1997) 6(1) Quality in Health Care 7.
} 
practitioner. Thoits notes that 'positional roles provide the individual with a sense of who they are and how they ought to behave'. ${ }^{100}$ Thus, frequently a role identity provides an individual with a meaning for self. ${ }^{101}$

In the context of the medical profession, Cruess et al assert that a doctor's identity is a 'representation of self, achieved in stages over time during which the characteristics, values, and norms of the medical profession are internalized, resulting in an individual thinking, acting and feeling like a physician'. ${ }^{102}$ Thus, Hobbs and Gabel argue, 'litigation is generally experienced as an assault on a physician's competence and integrity. ${ }^{103}$ In this research, all medical professional bodies, and a number of barristers spoke of the impact of litigation on the professional identity of the medical practitioner. ${ }^{104}$ Illustrating the impact litigation can have on the professional identity of the medical practitioner, one barrister recalled a case against a medical practitioner who was the lead physician in their speciality and noted the impact the claim had on that physician:

As far as this [physician] was concerned, this was their life's work, this was their legacy... and the fact of the allegation was that this individual ignored what was the essence of their specialty... We settled the case because it was strategically the right thing to do... The [physician] was very cool about things, and they said: 'I understand how things work... but it's tugging at my heart strings, because this is my life's work and what's being said here couldn't be further from the truth'... So it has a massive impact psychologically, certainly you feel that there is an attack being made on your professional reputation. (Barrister 3)

It was also recognised that the desire for perfectionism also plays a role in this context. Hilfiker has observed that 'the medical profession seems to have no place for its mistakes'. ${ }^{105}$ Speaking about the impact of medical negligence litigation on a medical practitioner's professional identity, Nash et al comment, 'their beliefs about "perfection" may influence the severity of the distress. ${ }^{106}$ Members of the ICGP focus group spoke about this, and concurred:

We're by nature, perfectionists and very conscientious, and for a lot of us that's our downfall... the identity of the doctor is very much rooted within themselves. As part of the process of becoming a professional, we take on the role of doctor in almost every cell in our body, even when we go on holidays we're still doctor, when we register in the hotel or check in, we become doctors 24 hours a day and if something happens... that goes to our very soul and it's very traumatic. (Group Member 1, ICGP)

In recognition of the impact of litigation on the professional identity of the medical practitioner, Denham has argued that litigation can damage 'their perception of themselves and their inner security. ${ }^{107}$ Thus, inextricably linked to the issue of professional identity and role identity is reputation, as

\footnotetext{
${ }^{100} \mathrm{PA}$ Thoits 'On merging identity theory and stress research' (1991) 54(2) American Sociological Association 105.

${ }^{101}$ MA Hogg et al 'A tale of two theories: a critical comparison of identity theory with social identity theory' (1995) 58(4) Social Psychology Quarterly 255.

${ }^{102}$ RL Cruess et al 'Reframing medical education to support professional identity formation' (2014) 89(11) Academic Medicine 1446 at 1447.

${ }^{103}$ T Hobbs and G Gable 'Coping with litigation stress' (1998) Physician's News Digest 1.

${ }^{104}$ The literature suggests that some specialities are more greatly exposed than others to the medico-legal environment: see for example DM Studdert et al 'Prevalence and characteristics of physicians prone to malpractice claims' (2016) 374 New England Journal of Medicine 354. In the context of this research, however, participants spoke to the phenomenon more generally. Thus, the findings and surrounding discussion do not focus on a particular medical speciality or length of time in practice.

${ }^{105}$ D Hilfiker 'Facing our mistakes' (1984) 310 New England Journal of Medicine 118 at 121.

${ }^{106} \mathrm{~L}$ Nash et al 'The psychological impact of complaints and negligence suits on doctors' (2004) 12(3) Australasian Psychiatry 278 at 280.

${ }^{107}$ CR Denham 'The five rights of the second victim' (2007) 3(2) Journal of Patient Safety 107 at 115.
} 
one impacts the other. Illustrating the impact medical negligence litigation can have on a medical practitioner's reputation and professional identity, participants noted:

If you think about the fact that their professional reputation is potentially on the line over it... just in one case, over a period of potentially a decade, it's absolutely devastating... even when we win they feel that they actually have not achieved anything because the salacious aspect of the litigation has sullied their reputation. (Barrister 3)

Gini has argued that an individual's work or profession 'forms us, gives us a focus, gives us a vehicle for personal expression and offers us a means for personal definition'. ${ }^{108}$ Accordingly, work-related identities are extremely important, ${ }^{109}$ and as the findings of this research suggest, the identity of the individual as a 'medical practitioner' is inherent in the conception of self. ${ }^{110}$

\section{(iii) Impact on professional role}

In addition to the impact medical negligence litigation has on the professional identity of the physician, the findings of this research also highlight the impact litigation may have on the professional role of the medical practitioner. To this effect, three issues were identified: first, medical practitioners may leave or 'drop out' from the profession as a result of litigation; secondly, fear of litigation may lead to 'drop out'; and lastly, litigation may lead to disenchantment with the profession.

All medical professional bodies spoke about the withdrawal of medical practitioners from the profession as a result of the stress and the impact of litigation. Scott et al have described this as 'dropping out', explaining that where medical practitioners find it difficult to 'move on' they may change their professional role, leave the profession or move to a different area of practice. ${ }^{11}$ Sandbar and Firestone have also noted that the stress of medical negligence litigation can result in 'dissatisfaction with medical practice leading to burnout and early retirement'. ${ }^{112}$ Similarly, Waterman et al have also reported that 'premature retirement' is a response to the adversarial system of litigation. ${ }^{113}$ In the present study all professional medical bodies reported the issue of 'dropping out' following litigation. Representing the views of the other members of the ICGP focus group, one participant reported:

It's destroyed some people... They've left medicine... Over the litigation and the length of the litigation... because it can drag on for years. (Group Member 3, ICGP)

These findings are in line with Charles and Franke's quantitative study of 154 doctors in the United States, which found that nearly one in five believed that their medical practice had suffered following litigation, and one-third considered retiring early as a result. ${ }^{114}$

The second issue identified by this research related to 'drop out' as a result of fear of litigation. Research has evidenced that fear of litigation can elicit behavioural and emotional responses. ${ }^{115}$ For example, Doran et al found that 25.4\% of 143 GPs surveyed in England left the profession early

\footnotetext{
${ }^{108} \mathrm{Al}$ Gini 'Work, identity and self: how we are formed by the work we do' (1998) 17(7) Journal of Business Ethics 707 at 708.

${ }^{109} \mathrm{MD}$ Johnson et al 'Multiple professional identities: examining differences in identification across work-related targets' (2006) 91(2) Journal of Applied Psychology 498.

${ }^{110} \mathrm{MG}$ Pratt et al 'Constructing professional identity: the role of work and identity learning cycles in the customization of identity among medical residents' (2006) 49(2) Academy of Management Journal 235.

${ }^{111}$ SD Scott et al 'The natural history for the healthcare provider "second victim" after adverse patient events' (2009) 18(5) Quality and Safety in Health Care 325 at 330.

${ }^{112}$ Sanbar and Firestone, above n 11.

${ }^{113}$ Waterman et al, above $\mathrm{n} 91$.

${ }^{114}$ S Charles and J Franke 'Sued and nonsued physicians' self-reported reactions' (1985) 1(42) American Journal of Psychiatry 437.

${ }^{115}$ Ibid.
} 
due to a fear of litigation. ${ }^{116}$ The present study also revealed that fear of potential litigation or adverse events can have a significant impact on medical practitioners, and in extreme incidences may cause them to leave the profession. Interestingly, participants in this research focused more on the adverse event in this context:

We've had a few people who actually changed career because they couldn't cope with that level of stress and that wasn't actually that they were going to be sued, but just the worry that things would go wrong or things would happen. (RCSI)

While respondents in this study did not differentiate between fear of adverse events and litigation as a reason for leaving the profession, research in this area suggests that fear of litigation can have a significant impact on a medical practitioner's decision to withdraw from the profession. ${ }^{117}$

The final theme which emerged in this research, in relation to the impact of litigation on the professional role of the medical practitioner, is the disenchantment of medical practitioners with the profession following litigation. Nash et al have argued that the impact of medical negligence litigation can result in behavioural changes. ${ }^{118}$ Similarly, behavioural changes were noted by all medical professional bodies, with one participant commenting:

You do see people who withdraw from the other stuff, so people who were involved in management in the hospital or teaching and training in the College. I think one of the reasons they withdraw from a lot of those things is you know because of this [impact of litigation]. I think they feel betrayed and they feel less impassioned and it's just a job to be done and they're less engaged. (RCSI)

The theme of disenchantment with the profession was also evident from the discourse within the ICGP focus group wherein participants discussed whether or not they would like their children to pursue a career in medicine. One member, representing the views of the others, reported:

[The adversarial environment is] certainly creating an attitude amongst doctors to say 'basically, if I was starting again I wouldn't go into medicine', and I've heard older doctors say 'I hope my children don't go into medicine'. Whereas, thirty years ago they would have encouraged that. (Group Member 3, ICGP)

These findings support Charles and Franke's argument that medical practitioners who have been subject to litigation are more likely to discourage their children from pursuing a career in medicine. ${ }^{119}$

\section{(iv) Impact on medical practice}

Having explored the nature and impact of litigation on the medical practitioner, it is also necessary to discuss the impact of litigation on the practice of medicine. The findings of this research indicate that litigation or fear of litigation can result in medical practitioners employing defensive medical practices. Sloan and Shadle explain that defensive medicine occurs when 'doctors order tests, procedures, or visits, or avoid certain high-risk patients or procedures' because of fear of litigation or complaints. ${ }^{120}$ In explaining the rationale for such practices, Brenner observes that medical practitioners practise defensive medicine in an attempt to avoid litigation, and in the belief that defensive

\footnotetext{
${ }^{116}$ N Doran et al 'Lost to the NHS: a mixed methods study of why GPs leave practice early in England' (2016) 66(643) British Journal of General Practice 128 at 132.

${ }^{117}$ Charles and Franke, above n 114; Doran et al, above n 116, at 132.

${ }^{118} \mathrm{Nash}$ et al, above $\mathrm{n} 106$, at 281.

${ }^{119}$ Charles and Franke, above n 114.

${ }^{120} \mathrm{~F}$ Sloan and J Shadle, 'Is there empirical evidence for "defensive medicine"? A reassessment' (2009) 28(2) Journal of Health Economics 481.
} 
practices will enable them to be 'a better and more insulated physician'. ${ }^{121}$ Similarly, Segal and Sacopulos comment:

Given the frequency of litigation, the length of time to resolution, and the impact such litigation has on the doctor's own health, the defensive practice of medicine is a natural outcome. ${ }^{122}$

Defensive medicine can be divided into two categories: 'positive' and 'negative'. ${ }^{123}$ Positive defensive medical practice is said to occur where 'physicians provide excessive and unnecessary diagnostic testing, treatment, hospitalization, or consultation'. ${ }^{124}$ In contrast, negative defensive medicine occurs where medical practitioners decline to supply or perform care that would be beneficial for the patient due to the fact that the procedure or the patient is viewed as 'high-risk'. ${ }^{125}$

Internationally, it has been reported that medical practitioners are increasingly practising defensively. ${ }^{126}$ Summerton has reported that there is a 'high correlation between defensive medical practice and the worry about being sued'. ${ }^{27}$ Similarly, in this research, all medical professional bodies, and a majority of legal practitioners cited the employment of defensive medical practices as a result of litigation or fear of litigation. In the context of this research, 'positive' defensive medical practices were most frequently cited.

It does drive people to do things differently. We would all feel that it drives people to investigate more. (RCSI)

You never recover [from litigation], and there's no question that you practise defensive medicine you can't take the risk and you refer more, you have more tests done, you change completely. (Group Member 2, ICGP)

The findings of this research indicate that some medical practitioners may practise defensive medicine as a result of litigation, and in some instances over fear of litigation. Whilst the majority of medical professional bodies spoke about 'positive' defensive practices, one medical professional body referred to the practice of 'negative' defensive medicine, where it was noted:

I think it has a significant impact on how people approach everything... I think it has a big impact on... the clinical risks they're prepared to take on and the amount of themselves that they're prepared to invest in these decisions and discussions. (RCSI)

It is possible that the reasoning behind only one medical professional body speaking about the practice of 'negative' defensive medicine is due to the fact that not all branches of the profession in Ireland may be engaging in 'negative' defensive medicine. Alternatively, it may be due to the fact that the group it represented (surgeons) are more likely to become defendants due to the high-risk procedures they

\footnotetext{
${ }^{121}$ Brenner, above n 89.

${ }^{122} \mathrm{JJ}$ Segal and M Sacopulos 'A modified no-fault malpractice system can resolve multiple healthcare system deficiencies' (2009) 467 (2) Clinical Orthopaedics and Related Research 420 at 421.

${ }^{123} \mathrm{D}$ Studdert et al 'Defensive medicine among high-risk specialist physicians in a volatile malpractice environment' (2005) 293(21) Journal of the American Medical Association 2609.

${ }^{124} \mathrm{MK}$ Sethi et al 'Incidence and costs of defensive medicine among orthopaedic surgeons in the United States: a national survey study' (2012) 41(2) American Journal of Orthopedics 69.

${ }^{125}$ WJ Thomas et al 'Low costs of defensive medicine, small savings from tort reform' (2010) 29(9) Health Affairs 1578.

${ }^{126} \mathrm{D}$ Montanera 'The importance of negative defensive medicine in the effects of malpractice reform' (2016) 17(3) The European Journal of Health Economics 355; V Prabhu 'Defensive medicine in neurosurgery' (2016) 95 World Neurosurgery 53; Pellino and Pellino, above n 10.

${ }^{127} \mathrm{~N}$ Summerton 'Positive and negative factors in defensive medicine: a questionnaire study of general practitioners' (1995) 310(6971) British Medical Journal 27 at 29.
} 
perform, as argued by Pellino et al. ${ }^{128}$ Consequently, as surgeons are typically involved in procedures that carry a greater risk than other medical specialities, it is possible that they are more susceptible to adopting 'negative' defensive medical practices.

Finally, it has been recognised that the practice of defensive medicine may extend to medical practitioners who are not involved in litigation. ${ }^{129}$ For example, Dranove and Watanabe argue, 'when physicians select a test or procedure, they must assess the probability of a malpractice claim... this assessment may be influenced by... the experiences of colleagues... ${ }^{, 130}$ Similarly, in Passmore and Leung's study of hospital psychiatrists in the North of England, 24\% of practitioners surveyed reported that they practised defensive medicine as a result of a previous legal claim against a colleague. ${ }^{131}$ The impact of litigation on other medical practitioners, and litigation as an impetus to adopt defensive medical practices was referred to by the majority of medical professional bodies in this research. Illustrating the impact of litigation on colleagues, one medical professional body commented:

I think that [defensive medicine] might happen to even colleagues around... I think it resonates with the whole system not just the individual... it affects the team, the doctor, the hospital and the entire system depending on the magnitude of the case. (RCPI)

It is argued that both 'positive' and 'negative' defensive practices are problematic. This is because 'positive' defensive medical practices place an increased burden on the healthcare system, generate unwarranted anxiety and expose patients to unnecessary risks; and 'negative' defensive medical practices may preclude patients from accessing life-saving treatments. ${ }^{132}$

\section{Elements of litigation which cause harm}

Whilst the literature suggests that litigation is always stressful for the parties involved, ${ }^{133}$ in 2000 Gutheil et al identified certain aspects of the litigation process, such as delay and adversarialism, which they argued can cause psychological and emotional damage, termed 'critogenic' (law-caused) harms. ${ }^{134}$

Building on Gutheil et al's framework, ${ }^{135}$ this section of the paper explores features of medical negligence litigation which can cause and/or exacerbate emotional harm, ${ }^{136}$ through a discussion of the empirical research findings and the literature. Interestingly, not all elements of the litigation process identified as a source of harm for the plaintiff were identified as sources of harm for medical practitioners. However, two aspects of litigation were identified as 'critogenic' harms for both the plaintiff and medical practitioner: (i) the adversarial nature of litigation; and (ii) the length of the litigation process. 'Re-traumatisation' was identified as a 'critogenic' harm for plaintiffs, and 'publicity' was identified as a 'critogenic' harm for medical practitioners. These harms will be discussed in the next section of this paper.

\footnotetext{
${ }^{128}$ Pellino and Pellino, above n 10.

${ }^{129}$ LD Hermer and H Brody 'Defensive medicine, cost containment, and reform' (2010) 25(5) Journal of General Internal Medicine 470.

${ }^{130} \mathrm{D}$ Dranove and Y Wantanabe 'Influence and deterrence: how obstetricians respond to litigation against themselves and their colleagues' (2010) 12(1) American Law and Economics Review 69 at 70.

${ }^{131} \mathrm{~K}$ Passmore and WC Leung 'Defensive practice among psychiatrists: a questionnaire survey' (2002) 78(925) Postgraduate Medical Journal 671 at 672 .

${ }^{132} \mathrm{O}$ Ortashi et al 'The practice of defensive medicine among hospital doctors in the United Kingdom' (2013) 14(1) BMC Medical Ethics 1 .

${ }^{133}$ Strasburger, above n 60; M Gramatikov 'A framework for measuring the costs of paths to justice' (2009) 2(1) The Journal Jurisprudence 111; ME Schatman and J Sullivan 'Whither suffering? The potential impact of tort reform on the emotional and existential healing of traumatically injured chronic pain patients' (2010) 3(3) Psychological Injury and Law 182.

${ }^{134}$ Gutheil et al, above n 7 .

${ }^{135}$ Ibid.

${ }^{136}$ Ibid.
} 


\section{(a) The adversarial nature of litigation}

\section{(i) The plaintiff}

As previously outlined, medical negligence claims are typically litigated in Ireland. ${ }^{137}$ By its very nature, the system is adversarial. However, it has been recognised that 'this structural feature may have destructive emotional impacts'. ${ }^{138}$ As Strasburger notes, 'no matter how sophisticated litigants may be, they are ultimately lay persons who have neither the education nor the experience' with litigation, and as such, 'few... are truly prepared for the forces of aggression that are released'. ${ }^{139}$ Similarly, in recognition of the aggressive nature of the adversarial process, one barrister stated that when meeting a potential client:

the first thing I would say to them is 'this is a fight to the death, you know'. (Barrister 1)

The view that medical negligence litigation is an aggressively adversarial process was reiterated by a large number of research participants:

[Litigation clearly becomes] a joust between two legal people... It's not really right [but] it's how it is. (Patients for Patient Safety)

I'm getting to the stage whereby I'm thinking litigation is nonsense... it's so aggressive, it's so aggressive in medical negligence actions. (Barrister 1)

Several barristers also referred to litigation as a 'game', reflecting the adversarial mindset inherent in the litigation process.

Once litigation commences... once the papers arrive at the barrister's desk, game on. (Barrister 3)

It is argued that the adversarial nature of litigation is problematic for two primary reasons. First, it makes the process conducive to 'a protracted, contentious, emotionally draining and expensive legal battle, ${ }^{140}$ and secondly, the aggressively adversarial nature of litigation is also inapposite to the extralegal goals of plaintiffs. ${ }^{141}$ For example, the adversarial system can further compound harm where goals such as an apology cannot be realised.

\section{(ii) The medical practitioner}

The adversarial nature of the litigation process was also recognised to have a 'destructive emotional impact $^{142}$ on the medical practitioner, as the majority of medical professional bodies and a number of barristers in this research identified the adversarial nature of medical negligence litigation as source of emotional harm to physicians. One point mooted by the medical professional bodies in relation to the adversarial nature of litigation, was the desire of medical practitioners involved in litigation to articulate their perspective, and the manner in which the adversarial system constrains this:

You know, a lot of what you feel is important gets dismissed... they will decide to settle or not to settle based on criteria which don't really include how the doctor feels about the whole thing. (RCSI)

\footnotetext{
${ }^{137}$ Boylan, above n 15.

${ }^{138}$ Gutheil et al, above $\mathrm{n} 7$, at 12 .

${ }^{139}$ Strasburger, above n 59, at 207.

${ }^{140} \mathrm{M}$ Boylan 'Medical accidents: is honesty the best policy? Time for a legal duty of candour?' (2012) 2 Medico-Legal Journal of Ireland 63.

${ }^{141} \mathrm{~T}$ Relis Perceptions in Litigation and Mediation: Lawyers, Defendants, Plaintiffs, and Gendered Parties (Cambridge: Cambridge University Press, 2009).

${ }^{142}$ Gutheil et al, above $n 7$, at 12 .
} 
Despite the fact that the findings of this research indicated that medical practitioners would like the option of inclusion in the litigation process, all barristers failed to display an appreciation of this perspective, demonstrating diametrically opposing views.

Generally speaking, when you're a defendant... nothing happens for vast periods of time and you don't hear anything and then maybe in two years you'll get a letter asking you for some information and then you don't hear anything for another two years, so it [the litigation process] doesn't bother them that much mostly... [but] obviously they'd prefer not to have to deal with it. (Barrister 10)

Thus, although the majority of barristers viewed the non-involvement of medical practitioners in litigation as positive, the discourse provided by both the professional medical bodies and the international literature challenges these assertions, and indicates that this can in fact compound emotional harm.

\section{(b) The length of litigation}

\section{(i) The plaintiff}

This research uncovered that another significant cause of 'critogenesis' is the length of the litigation process. ${ }^{143}$ The issue of delay arose repeatedly in the course of this research, where the majority of participants cited the duration of litigation as a factor which significantly contributes to the stress of the process. In Ireland, medical negligence litigation is typically prolonged, ${ }^{144}$ and whilst the correlation between cost and delay is clear, ${ }^{145}$ it is more difficult to quantify the impact of prolonged litigation on the psychological wellbeing of the plaintiff. Altmaier and Meyer have argued that delay not only equates to loss of time and money for both parties to the dispute, but may also have a grave emotional impact, as delay can increase the risk of mental health instability and psychological damage. ${ }^{146}$ The problematic nature of delay in this context was recognised by a large majority of participants.

Years of trauma and uncertainty, because again while it's business as usual for the other individuals, it's there with you $24 / 7$... years of that trauma and uncertainty. (Patients for Patient Safety)

So whilst we can put it on the back burner as such and forget about it for 5 or 6 years the plaintiff is still waiting and wondering what's happening. Doctors and clinical staff are wondering what's happening. (Barrister 2)

Delay in attempts to reach a negotiated settlement was also identified as problematic. Although it has reported that less than $3 \%$ of medical negligence claims result in a contested court hearing in Ireland, ${ }^{147}$ the findings of this research uncovered that the adversarial approach adopted means that frequently efforts to resolve medical negligence claims only occur once a trial date has been obtained. Not only does this do little to reduce the length and cost of litigation, it can also cause and compound emotional harm. This was noted by the majority of participants.

Bringing you literally to the steps of the Courthouse, that wearing down process. (Patients for Patient Safety)

\footnotetext{
${ }^{143} \mathrm{D}$ Shuman 'When time does not heal: understanding the importance of avoiding unnecessary delay in the resolution of tort cases' (2000) 6(4) Psychology, Public Policy and Law 880.

${ }^{144}$ Dowling-Hussey, above n 37.

${ }^{145}$ DA Hyman and C Silver 'Medical malpractice litigation and tort reform: it's the incentives, stupid' (2006) 59 Vanderbilt Law Review 1085.

${ }^{146}$ E Altmaier and M Meyer Applied Specialities in Psychology (Crown Publishing Group, 1985).

${ }^{147}$ National Treasury Management Agency Annual Report and Accounts 2018 p 43.
} 
Finally, whilst delay can be identified as a law-caused harm, it should be noted that the impact of delay is likely to vary depending on the stakes involved in a case. For example, Strasburger and Kritzer note that where an award of damages is required for ongoing care, the stakes in the litigation will be higher, and as a result, accompanying litigation-stress will be intensified. ${ }^{148}$ In contrast, where an individual is litigating to address a perceived wrong, levels of stress are unlikely to be as intense. ${ }^{149}$ This is primarily because the continuation of normal everyday life is not dependent on an award of damages. Thus, in instances where the cost of care is an ongoing issue, it is likely that delay will be particularly problematic and damaging to the physical and psychological well-being of the litigant. ${ }^{150}$

\section{(ii) The medical practitioner}

The impact of delay on the plaintiff, in the context of medical negligence litigation, may be clearer and more easily ascertained than the impact on the medical practitioner. This is because, and as Shuman notes, traditionally, delay was viewed favourably by defendants, wherein it was hoped the claim may disappear. ${ }^{151}$ Similarly, Genn has argued that 'delay is an advantage' to defendants, as plaintiffs may lose interest in the litigation or run out of money. ${ }^{152}$ Expanding on these arguments, one barrister commented:

No defendant is going to push it [the case] because they'll hope it will go away. (Barrister 9)

However, Ryll in her critique on delay has noted 'litigation causes a tremendous amount of personal exposure' to medical practitioners, and 'emotional wounds are kept open by the long and arduous litigation process, delaying healing. ${ }^{153}$ Similarly, in the context of this research, all medical professional bodies, and a number of barristers identified delay as an aspect of the litigation process which can cause harm to medical practitioners who are subject to litigation:

A lot of the problem with medico-legal cases is that this process starts and then you respond and then nothing happens and nothing happens and nothing happens... but it doesn't stop, it just sits there. At least if it gets to a trial it will get finished, but you just get an opened case that doesn't get resolved and that's definitely a cause for concern for people. (RCSI)

Brenner has observed that once litigation commences, the case will remain continually on the medical practitioner's mind. ${ }^{154}$ All members of the ICGP focus group spoke to this:

[The length of the litigation is a] huge stressor, I mean you're trying to cope with your practice every day, but it's still at the back of your mind. (Group Member 3, ICGP)

These findings indicate that the length of medical negligence litigation is a significant factor resulting in litigation-induced harm to the medical practitioner. As Brenner states, 'there is a huge emotional toll that occurs from the long multiyear process'. ${ }^{155}$ Similarly, Shuman succinctly explains, 'the longer these claims remain unresolved, the longer these defendants live with... dominant debilitating stress.'. ${ }^{156}$

\footnotetext{
${ }^{148}$ Strasburger, above n 59; H Kritzer 'Adjudication to settlement: shading in the gray' (1986) 70 Judicature 161.

${ }^{149}$ Strasburger, above n 59.

${ }^{150} \mathrm{P}$ Fenn and N Rickman 'Delay and settlement in litigation' (1999) 109(457) The Economic Journal 476.

${ }^{151}$ Shuman, above $\mathrm{n} 143$, at 894 .

${ }^{152} \mathrm{H}$ Genn Judging Civil Justice (Cambridge: Cambridge University Press 2010) p 111.

${ }^{153}$ Ryll, above n 82 , at 36 .

${ }^{154}$ Brenner, above n 89.

${ }^{155}$ Ibid.

${ }^{156}$ Shuman, above n 143 , at $894-895$.
} 


\section{(iii) Re-traumatisation (plaintiff)}

Medical negligence claims are complex and, as such, require involvement from the plaintiff. For example, once litigation commences, the plaintiff will usually have to engage fulsomely with the process as pleadings, discovery and expert evaluations all require participation from the plaintiff. ${ }^{157}$ In addition, the plaintiff is likely to be examined by multiple medico-legal experts, retained by both the legal team of the plaintiff and defendant. ${ }^{158}$ Such involvement inevitably forces the plaintiff to re-live the event which caused the damage or injury, and is central to the litigation. Gutheil et al note that each stage of the litigation process can 'reawaken the original traumatic event in the plaintiff s mind, to force re-experiencing it and... produce a retraumatization'. ${ }^{159}$ As Hepler surmises:

[T] hroughout the entire process [of litigation] the victim must relive the event, re-experience the pain, and in general, remain almost frozen in time until the claim is resolved. ${ }^{160}$

Participants in this research spoke of the issue of re-traumatisation, noting that the claim remains with the plaintiff until it reaches conclusion.

Time and time again you're re-living the events... You are going over the questions 'what could have been done differently? What if? What if? What if?' And that keeps pounding in your head, day in, day out. (Patients for Patient Safety)

Due to the nature of the harm suffered, from a health perspective, medical negligence litigation frequently involves individuals who are vulnerable. ${ }^{161}$ In these cases the plaintiff will be particularly exposed to further emotional distress as they have to re-live the event complained of, which is typically focused on injury and damage and, therefore, often has an obvious emotional consequence. ${ }^{162}$

\section{(iv) Publicity (medical practitioner)}

The final element of litigation which was recognised as a factor of the process which can cause emotional harm to medical practitioners is publicity. Charles asserts, 'the amount of surrounding publicity... play[s] a role in generating stress'. ${ }^{163}$ This is because, as Ryll argues, medical negligence litigation 'symbolizes a personal assault, a psychological event that generates stress causing emotional... responses'. ${ }^{164}$ Similarly, this research found that the public nature of medical negligence actions can be extremely stressful for medical practitioners. A large majority of barristers and all medical professional bodies spoke of the distress caused by publicity.

The media tries to, I suppose, paint them as if they don't care. But I mean most doctors go into the profession to help, so when something like that happens they struggle. (RCPI)

If we take a case to trial... they realise then that it is public and the publicity that goes with it, irrespective of whether they're exonerated, can be quite damaging to them. (Barrister 7)

Charles argues that as medical practitioners are often self-critical, they are especially vulnerable to the criticisms and arguments made during the litigation process which can be exacerbated by media

\footnotetext{
${ }^{157}$ Ennis and Vincent, above $\mathrm{n} 98$.

${ }^{158}$ McGrory v Electricity Supply Board [2003] IESC 45; Boylan, above n 141, at 138.

${ }^{159}$ Gutheil et al, above $\mathrm{n} 7$, at 13 .

${ }^{160}$ Hepler, above n 74 .

${ }^{161}$ SJ Spero 'Boundary violations and malpractice litigation' (2008) 25(4) Psychiatric Times 1.

${ }^{162} \mathrm{G}$ Fulcher 'Litigation-induced trauma sensitisation (LITS) - a potential negative outcome of the process of litigation' (2004) 11(1) Psychiatry, Psychology and Law 79.

${ }^{163}$ Charles, above $\mathrm{n} 83$, at 56.

${ }^{164}$ Ryll, above n 82 , at 36 .
} 
coverage of the dispute. ${ }^{165}$ As Sloan et al note, 'publicity about $\mathrm{a}[\mathrm{n}]$... award... may be embarrassing and/or be taken by others as an indicator of the physician's quality. ${ }^{166}$ The findings of this research support these arguments, as they indicate that, in the Irish context, publicity surrounding litigation is a significant factor which can cause emotional harm.

\section{Reform proposals}

The findings of this research highlight significant shortcomings with the current dynamic of medical negligence litigation in Ireland. In particular, the findings illustrate the destructive emotional impact medical negligence litigation can have on those involved. A number of reviews of the law in this area over the past ten years demonstrate awareness that the current system is unsatisfactory. However, to date, such reviews have predominantly focused on the temporal and financial burdens associated with this form of litigation. Reforms have been mooted in this area, most notably by the High Court Working Group on Medical Negligence and Periodic Payment Orders, which made recommendations over the course of three reports, particularly in relation to pre-action protocols and case management, with a view to ameliorating the financial and temporal burdens associated with these disputes. The Law Reform Commission has also examined this area and recommended the introduction of mediation in medical negligence disputes. ${ }^{167}$ Whilst a detailed discussion on reform measures is outside the scope of this paper, it is prudent to briefly address these measures and their potential capacity to ameliorate some of the emotional burdens identified in this paper.

Following an in-depth analysis of the operation of pre-action protocols in England and Wales, ${ }^{168}$ the High Court Working Group, in its second report, recommended the introduction of pre-action protocols in medical negligence disputes in Ireland. ${ }^{169}$ The Group outlined benefits of the introduction of such a process to include: the potential for early resolution of the dispute via negotiated settlement or alternative dispute resolution, which would have the effect of reducing the number of claims which ultimately proceed to litigation; and where a claim did proceed to litigation, a pre-action protocol would assist in identifying the issues which should ultimately be in dispute, at a much earlier stage. ${ }^{170}$ The recommendation of the Working Group was put on a statutory footing by virtue of section 32B of the Civil Liability and Courts Act 2004, as inserted by the Legal Services Regulation Act $2015,{ }^{171}$ which provides that such protocols must be completed before litigation can be pursued. ${ }^{172}$ However, this section is yet to be brought into force, and specifics as to what the pre-action protocols will encompass are still awaited. ${ }^{173}$ Whilst the introduction of pre-action protocols is unlikely to completely address all the issues identified by this research, the protocols appear to have the capacity to minimise the burdens of medical negligence litigation by encouraging collaboration rather than zealous advocacy, and reducing the length of the process. ${ }^{174}$ It is disappointing however, that such provisions have not yet been brought into force more than four years since the passage of the legislation.

\footnotetext{
${ }^{165}$ Charles, above $\mathrm{n} 83$, at 56.

${ }^{166}$ FA Sloan and CR Hsieh 'Variability in medical malpractice payments: is the compensation fair?' [1990] Law and Society Review 997 at 1001.

${ }^{167}$ Law Reform Commission Alternative Dispute Resolution: Mediation and Conciliation [LRC 98-2010].

${ }^{168}$ High Court Working Group on Medical Negligence and Periodic Payments Report on Pre-action Protocols (Module 2) (2012) p 11.

${ }^{169}$ Ibid, p 29.

${ }^{170}$ Ibid, p 7.

${ }^{171}$ Section $32 \mathrm{~B}(1)$ : 'There shall be a pre-action protocol relating to clinical negligence actions'.

${ }^{172}$ Section $32 \mathrm{~B}(2)$ : 'The pre-action protocol shall include requirements that must be complied with by the parties to clinical negligence actions before such actions are brought'.

${ }^{173}$ Section $32 \mathrm{~B}(3)$ provides that the Minister for Health shall 'by regulations make provision specifying the terms of the pre-action protocol'.

${ }^{174}$ It is interesting to note that whilst such pre-action protocols have been broadly welcomed in England and Wales and observed to encourage collaboration, some commentators have cautioned about the frontloading of costs. See for example Lord Justice Jackson Review of Civil Litigation Costs Final Report (2010); M Ahmed 'The pre-action protocols are a significant
} 
Another tool which may be employed to ensure the efficient resolution of litigation and minimise delay is the use of case management, which would give the court the responsibility of supervising the progress of medical negligence litigation during which time parties are subject to certain procedures, with the view of achieving quicker resolution. In addition to pre-action protocols, the High Court Working Group recommended the introduction of case management in instances where medical negligence disputes proceeded to litigation. ${ }^{175}$ The Group was of the view that both pre-action protocols and case management needed to be implemented in tandem, as case management would not work in the absence of protocols. ${ }^{176}$ Given the findings of this research in relation to the impact of litigation, and the identification of the duration of the process as a 'critogenic' harm, the introduction of strict time limits is to be welcomed. Ultimately, although the Working Group recommended the introduction of case management in medical negligence litigation, they advised against the automatic referral of cases to a system of case management due to limited judicial resources, and instead argued it should be available on the application of the parties or on the courts own initiative. ${ }^{177}$ It is regretful that the Working Group advised against the automatic referral of medical negligence cases to case management, given the prevalence of legal adversarialism.

A final reform measure which is worthy of brief consideration is the alternative dispute resolution process of mediation. The recognition of mediation as a formal method of dispute resolution began several decades ago in the United States, in what Auerbach refers to as the 'legalisation of informal alternatives'. ${ }^{178}$ Mediation gained further prominence internationally following Lord Woolf's report on the civil justice system in England and Wales, where he famously argued that litigation was to be 'avoided wherever possible'. ${ }^{179}$ Mediation has the capacity to resolve medical negligence disputes in an economically efficient and non-contentious manner. ${ }^{180}$ Such a process, therefore, has the potential to alleviate some of the burdens associated with the traditional process of medical negligence litigation. Echoes of the Woolf reforms were gradually felt in Ireland; however, these changes emerged slowly. ${ }^{181}$ As previously mentioned, the Law Reform Commission recommended the introduction of mediation in medical negligence disputes, ${ }^{182}$ and many recommendations of the LRC are encompassed in the Mediation Act 2017. The Mediation Act $2017^{183}$ was brought into force in January 2018, and places an obligation on legal practitioners to inform clients of the potential of mediation to resolve their dispute prior to issuing proceedings. ${ }^{184}$ Thus, whilst mediation has been recognised as being underused in a medical negligence context, ${ }^{185}$ it is hoped that the 2017 Act will result in a change to the current dynamic of these disputes, given the potential of the process to minimise harm. ${ }^{186}$

\footnotetext{
procedural aspect of the English civil justice system but reform is required: Jet2 Holidays Ltd v Hughes [2019] EWCA Civ 1858' (2020) 39(3) Civil Justice Quarterly 193.

${ }^{175}$ High Court Working Group on Medical Negligence and Periodic Payments Report on Case Management (Module 3) (2013) p 5.

${ }^{176}$ Ibid, p 5.

${ }^{177}$ Ibid, p 13.

${ }^{178}$ J Auerbach Justice without Law? (Oxford: Oxford University Press 1983) p 123.

${ }^{179}$ Lord Woolf 'Access to Justice Part II: Final Report' (Lord Chancellor's Department, 1996) para 10.

${ }^{180} \mathrm{SM}$ Johnson 'The case for medical malpractice mediation' (2000) 5 Journal of Law and Medicine 21; D Cott 'Bad medicine and worse resolutions: why the HSE should embrace mediation as a response to medical negligence claims' (2012) 12 University College Dublin Law Review 89.

${ }^{181}$ See for example Civil Liability and Courts Act 2004, s 15 which provides for mediation in personal injury cases, where upon application of a party to an action, the court can 'direct' the parties to attend a 'mediation conference'.

${ }^{182}$ Law Reform Commission Alternative Dispute Resolution: Mediation and Conciliation [LRC 98-2010].

${ }^{183}$ The Act was designed to encourage the use of mediation to resolve commercial, family, and civil disputes (including medical negligence).

${ }^{184}$ Mediation Act 2017, s 14(1).

${ }^{185}$ The reasons for which remain unexplored. See generally Dowling-Hussey, above n 37.

${ }^{186}$ It should be noted that whilst the obligations under the Act may increase uptake of mediation in medical negligence disputes, several commentators have highlighted other barriers to mediation, for example, dominant legal culture. For further discussion, see Relis, above n 142.
} 


\section{Conclusion}

Medical negligence litigation is a complex, fluid, business. This paper has explored the impact of medical negligence litigation on its participants, and identified aspects of the litigious process which may cause and/or exacerbate harm. The findings of this research indicate that litigation is an extremely stressful process for all involved, and can have a profound emotional impact on its participants. As previously noted, reform proposals and measures to date have been aimed at ameliorating the financial and temporal burdens associated with medical negligence litigation. Whilst the financial and temporal efficiency of the process is important, the findings of this qualitative study evidence a need for reform beyond these concerns. The findings also highlight the need for supports for physicians who are subject to medical negligence litigation.

Cite this article: Tumelty M-E (2021). Exploring the emotional burdens and impact of medical negligence litigation on the plaintiff and medical practitioner: insights from Ireland. Legal Studies 41, 633-656. https://doi.org/10.1017/lst.2021.20 